\title{
In Utero Exposure to Helminth and Mycobacterial Antigens Generates Cytokine Responses Similar to That Observed in Adults
}

\author{
Indu Malhotra, ${ }^{\star}$ John Ouma, ${ }^{\ddagger}$ Alex Wamachi, ${ }^{\S}$ John Kioko, ${ }^{\ddagger}$ Peter Mungai, ${ }^{\ddagger}$ Adams Omollo, ${ }^{\ddagger}$ Lynne Elson, ${ }^{\star}$ Davy Koech, ${ }^{\S}$ \\ James W. Kazura, ${ }^{*}$ and Christopher L. King* \\ *Division of Geographic Medicine, Department of Medicine, Case Western Reserve University and University Hospitals of Cleveland, \\ Cleveland, Ohio 44106-4983; ${ }^{\ddagger}$ Division of Vector Borne Diseases, Nairobi, Kenya; and ${ }^{\S}$ Kenya Medical Research Institute, \\ Nairobi, Kenya
}

\begin{abstract}
Neonates exposed to parasite antigens (Ags) in utero may develop altered fetal immunity that could affect subsequent responses to infection. We hypothesized that cord blood lymphocytes (CBL) from offspring of mothers residing in an area highly endemic for schistosomiasis, filariasis, and tuberculosis in Kenya would either fail to respond or generate a predominantly Th2-associated cytokine response to helminth and mycobacterial antigens (PPD) in vitro compared to maternal PBMC. Kenyan CBL generated helminth Agspecific IL-5 (range 29-194 pg/ml), IL-10 (121-2,115 pg/ml), and/or IFN- $\gamma(78 \mathrm{pg} / \mathrm{ml}-10.6 \mathrm{ng} / \mathrm{ml})$ in 26,46 , and $57 \%$ of neonates, respectively $(n=40)$. PPD induced IFN- $\gamma$ in $30 \%$ of Kenyan CBL (range 79-1,896 pg/ml), but little or no IL-4 or IL-5. No Ag-specific IL-4, IL-5, or IFN- $\gamma$ release was detected by CBL obtained in the United States $(n=11)$. Agdriven cytokine production was primarily CD4-dependent. Cytokine responses to helminth and mycobacterial Ags by maternal PBMC mirrored that observed in neonates. $\mathrm{CBL}$ from helminth infected and/or PPD-sensitized mothers produced more Ag-specific cytokines compared to CBL from uninfected mothers $(P<\mathbf{0 . 0 5})$. These data demonstrate that the human fetus develops similar patterns of cytokine production observed in adults and indicates that prenatal exposure may not lead to tolerance or altered fetal immunity. $(J$. Clin. Invest. 1997. 99:1759-1766.) Key words: schistosomiasis • filariasis • tuberculosis • neonates • cytokines
\end{abstract}

\section{Introduction}

In utero exposure to helminth antigens $(\mathrm{Ags})^{1}(1,2)$ or to autologous lymphocytes $(3,4)$ has been postulated to induce immune tolerance in neonates $(5,6)$. Therefore after birth, when individuals become infected, their lymphocytes failed to recog-

Address correspondence to Christopher L. King, Division of Geographic Medicine, Case Western Reserve University School of Medicine, Room W137, 2109 Adelbert Road, Cleveland, OH 44106-4983. Phone: 216-368-4817; FAX: 216-368-4825.

Received for publication 21 October 1996 and accepted in revised form 23 January 1997.

1. Abbreviations used in this paper: $\mathrm{Ag}$, antigen; $\mathrm{BrmA}$, Brugia malayi filarial antigen; CBL, cord blood lymphocyte; PPD, mycobacterial antigen; SWAP, Schistosoma haematobium worm antigen.

J. Clin. Invest.

(C) The American Society for Clinical Investigation, Inc.

0021-9738/97/04/1759/08 \$2.00

Volume 99, Number 7, April 1997, 1759-1766 nize parasite antigens and accommodate the parasite to a greater degree than an individual from an uninfected mother. Because acute disease and subsequent pathology are immunologically mediated in chronic helminth infections such as lymphatic filariasis or schistosomiasis $(7,8)$ this tolerance might produce a milder disease and reduced pathology.

Epidemiological evidence indicates that the pattern of disease and pathology in human schistosomiasis or filariasis relates to previous exposure and immunologic experience to the parasite. Individuals who move from nonendemic to endemic areas such as migrants, travelers, or military personnel often experience more severe acute disease and subsequent pathology than indigenous populations (9-13). In human lymphatic filariasis, for example, development of asymptomatic infection has been directly linked to a maternal, but not a paternal history of active filarial infections (14), and children borne of filarial-infected mothers have been shown to have impaired filarial Ag-specific T cell responses (6). These observations support the hypothesis that prenatal exposure may affect development of subsequent immune responses.

Studies of animal models infected with helminth parasites also show that their offspring have altered immunity to subsequent infection. In utero exposure to the nematode parasites Dipetalonema viteae, Brugia malayi, or Acanthocheilonema viteae enhanced the offspring's susceptibility to subsequent infection by these parasites and produce impaired spleen cell responsiveness to $\mathrm{T}$ cell mitogens and filarial antigens (15-17). In murine models of schistosomiasis or filariasis, offspring of infected mothers developed smaller granulomas $(1,18)$ or reduced gross lymphatic pathology (2) compared with newborns of uninfected mothers. Other studies have shown that immunizing newborn mice to allogenic splenocytes or other antigens also induced immunologic tolerance (3) by a mechanism of clonal anergy or depletion.

No human studies have directly shown that in utero exposure to a pathogen affects subsequent outcome of disease. Prenatal exposure to infection or to various Ags does, however, lead to immunologic sensitization in human newborns. Offspring of mothers infected with mumps or toxoplasmosis during pregnancy develop Ag-specific antibody responses and memory $\mathrm{T}$ cells $(19,20)$. Immunization of pregnant mothers with tetanus toxoid, streptococcal, or meningococcal vaccines also induces antibody and $\mathrm{T}$ cell responses in neonates that persist into childhood (21-23). Prenatal sensitization also occurs with schistosome and filarial infections. Offspring of schistosome-infected mothers $(a)$ develop skin test reactivity to schistosome Ags shortly after birth (24, 25), (b) their cord blood lymphocytes (CBLs) proliferate in response to parasite Ags or antiidiotypic Abs, and $(c)$ their sera contain parasitespecific IgE or IgM antibodies (5, 26-28). The mechanisms by which in utero exposure leads to antigen-specific hyporespon- 
siveness when existing data show that neonates become sensitized in utero has not been addressed. One possibility is suggested by studies in mice that demonstrate neonatal immunization preferentially induces Ag-specific Th2- rather Th1associated cytokine responses compared to immunization later in life (29). This could result in cross-modulation with the result that $\mathrm{T}$ cell proliferation and IFN- $\gamma$ production are impaired. The present study examines whether neonates exposed in utero to helminth and mycobacterial Ags develop Ag-specific immunity and a similar bias toward Th2-associated cytokine responses. We predicted that helminth Ags (which produce a characteristically mixed Th2- and Th1-associated cytokine production) and PPD (a Th1-associated cytokine response) would both stimulate a predominantly Th2-associated response by CBLs compared to PBMC obtained from their mothers.

\section{Methods}

Study population. Paired cord and maternal blood samples were collected at Msambweni District Hospital in the Coast Province, Kenya. Consent was obtained from mothers before collection of samples. Pregnant mothers that delivered at the hospital came from neighboring communities with high prevalences of Schistosoma haematobium, Wuchereria bancrofti, and/or mixed intestinal helminth infection, predominantly Trichuris trichuris, Anclystoma species, and Ascaris lumbricoides. Venous blood, stool samples, and urine specimens were obtained from mothers before delivery. Umbilical cord blood of full-term newborns from uncomplicated pregnancies were collected at delivery. Cord blood was also obtained from eleven healthy North American deliveries as controls. Sera or plasma were stored at $-70^{\circ} \mathrm{C}$. Maternal infection status was determined by filtration of urine or anticoagulated peripheral venous blood filtration through a nucleopore filter for schistosomiasis or filariasis, respectively. Filarial antigen detection in the serum was performed using an ELISA based on the $\mathrm{mAb} \mathrm{Og} 4 \mathrm{C} 3$ according to the manufacturer's instructions (Trop-Ag W. Bancrofti assay; James Cook University Tropical Biotechnology Pty Ltd., Townsville, Queensland, Australia).

Ags and mitogens. Schistosoma haematobium worm Ag (SWAP) and filarial Ag from Brugia malayi (BmA) were prepared as a saline extract of adult-stage parasites $(30,31)$. Endotoxin in these preparations was $<0.5 \mathrm{ng} / \mathrm{ml} ; 5-50$-fold less than that required for LPS stimulation of cytokines from human lymphocytes (32). Mycobacterial $\mathrm{Ag}$, purified protein derivative (PPD) (Stats-Serum Institute, Copenhagen, Denmark), and PMA with ionomycin (Calbiochem Corp., La Jolla, CA) were used in parallel cultures.

Isolation of PBMC and culture conditions for in vitro cytokine production. All studies were performed on fresh PBMC separated by density gradient centrifugation on Ficoll-Hypaque from heparinized cord and venous blood and resuspended in RPMI-1640 supplemented with $10 \%$ FCS, $4 \mathrm{mM}$ L-glutamine, $25 \mathrm{mM}$ Hepes, and $80 \mu \mathrm{g} / \mathrm{ml}$ gentamicin (C-RPMI; BioWhittaker, Inc., Walkersville, MD). PBMCs were cultured at $2 \times 10^{6}$ cells $/ \mathrm{ml}$ in C-RPMI in a total volume of $1 \mathrm{ml}$. To duplicate cultures were added either media alone, SWAP $(50 \mu \mathrm{g} /$ $\mathrm{ml}), \mathrm{BmA}(10 \mu \mathrm{g} / \mathrm{ml})$, PPD $(10 \mu \mathrm{g} / \mathrm{ml})$, or PMA, $50 \mathrm{ng} / \mathrm{ml}$ with ionomycin (at $1 \mu \mathrm{g} / \mathrm{ml})$. Cells were incubated at $37^{\circ} \mathrm{C}$ in $5 \% \mathrm{CO}_{2}$ and supernatants collected at 24,48 , and $72 \mathrm{~h}$ and immediately frozen at $-70^{\circ} \mathrm{C}$ for subsequent determination of cytokine production.

Cytokine production by CBL subsets. To assess cytokine production by lymphocytes subpopulations, CBLs were washed once in cold RPMI with $2 \%$ FBS. CD4+ cell depletion was performed using magnetic beads directly conjugated to anti-CD4 Abs (Dynal Inc., Lake Success, NY). Immunomagnetic depletion was performed according to manufacturers' instructions and routinely $>85 \% \mathrm{CD} 4+$ cells were removed from whole CBLs. CD4+ cells were also enriched by immunomagnetic positive selection (DETACHeBEAD, Dynal Corp.) based on the manufacturer's instructions and incubated at $2 \times 10^{6} / \mathrm{ml}$ with $2 \times 10^{5} / \mathrm{ml}$ PBMC depleted of T cells added as APC in 96-well microtiter plates. Positively selected cells contained $>95 \%$ CD4+ cells.

Cytokine and immunoglobulin ELISAs. Cytokine levels in cell supernatants were measured by ELISA and expressed in $\mathrm{pg} / \mathrm{ml}$ by interpolation from standard curves based on recombinant lymphokines using antibodies and methods previously described (33). Antibody pairs for capture and detection (all biotinylated) for the cytokines studied were as follows respectively: IL-5, TRFK5, and 5D10 (PharMingen, San Diego, CA); IL-4, 8D4, and 25D2 (PharMingen); IFN- $\gamma$, M-700, and M-701 (Endogen, Inc., Cambridge, MA); IL-10 18551D, and 18652D (PharMingen). The limits of detection for each cytokine ELISA were $18 \mathrm{pg} / \mathrm{ml}$ for IL-5, $16 \mathrm{pg} / \mathrm{ml}$ for IL-4, $10 \mathrm{pg} / \mathrm{ml}$ for IFN- $\gamma$, and $16 \mathrm{pg} / \mathrm{ml}$ for IL-10. The ELISAs for parasite-specific $\mathrm{IgG} 4$ and $\mathrm{IgE}$ were performed with SWAP and BmA antigen as described previously (34).

ELISPOT procedure. The ELISPOT assays were modified from the assays as previously described (35). T-spot plates (Athersys Corp., Cleveland, $\mathrm{OH}$ ) were coated with capture antibodies in sterile PBS overnight at $4^{\circ} \mathrm{C}$ and blocked with C-RPMI with $10 \%$ FCS. Plates were then washed three times with sterile PBS. Single-cell suspensions were prepared, counted, and transferred to the plate at 200 $\mu \mathrm{l} /$ well; incubated at $37^{\circ} \mathrm{C}$ with $5 \% \mathrm{CO}_{2}$ for $24 \mathrm{~h}$ for IL-4 and IFN- $\gamma$, and $48 \mathrm{~h}$ for IL-5 and IL-10. For Ag-specific cytokine production $0.5-$ $1 \times 10^{6}$ cells were added per well. For mitogen-driven cytokine production this was reduced to $0.1-1 \times 10^{5}$ cells/well. The wells were run in duplicate if there were enough cells. After incubation, plates were washed three times with PBS followed by three washes with PBSTWEEN $(0.05 \%)$. Detecting antibodies were added and incubated overnight at $4^{\circ} \mathrm{C}$. The resulting spots were initially enumerated with a dissecting microscope $(\times 5-20)$ and numbers verified by a T Spot Image Analyzer (Athersys) that is designed to detect ELISPOTS using predetermined criteria based on size, shape, and colorimetric density.

\section{Results}

Cord blood levels of polyclonal and parasite-specific IgE. To determine whether neonates become sensitized in utero, the levels of parasite-specific and total IgE levels in cord sera were examined because this isotype does not cross the placenta. Polyclonal and parasite-specific IgE were present in many Kenyan cord and maternal sera and undetectable in cord blood sera from North American infants (Fig. 1). Because the possibility existed that fetal cord blood may have been contaminated from transplacental passage of maternal blood at the time of birth, we examined the ratios of parasite-specific $\operatorname{IgE}$ to total $\operatorname{IgE}$ in paired cord and maternal sera as previously described (5). Typically, serum parasite-specific IgE levels in adults are less than 5\% of total IgE levels (31) and much higher than in cord sera. Parasite-specific IgE contributes a much larger proportion of the neonate's total $\operatorname{IgE}$ than in adults because of its more limited antigenic exposure (Fig. 2). If significant mixing of maternal and fetal blood did occur, the proportion of parasite-specific IgE in the cord sera should be equal to that observed in maternal sera; this result was observed in 4 of 30 serum pairs; but in 26 of 30 serum pairs, the amount of BmA-specific IgE in cord blood was greater (threefold or more) than maternal, indicating $\mathrm{IgE}$ was produced in utero (Fig. 2). Similar results were observed for SWAP-specific IgE in cord sera (data not shown).

Helminth and mycobacterial Ag-induced cytokine production by $C B L$. To determine whether Ag-specific lymphocytes develop in neonates and their pattern of cytokine production, CBLs from North American and Kenyan offspring were stim- 


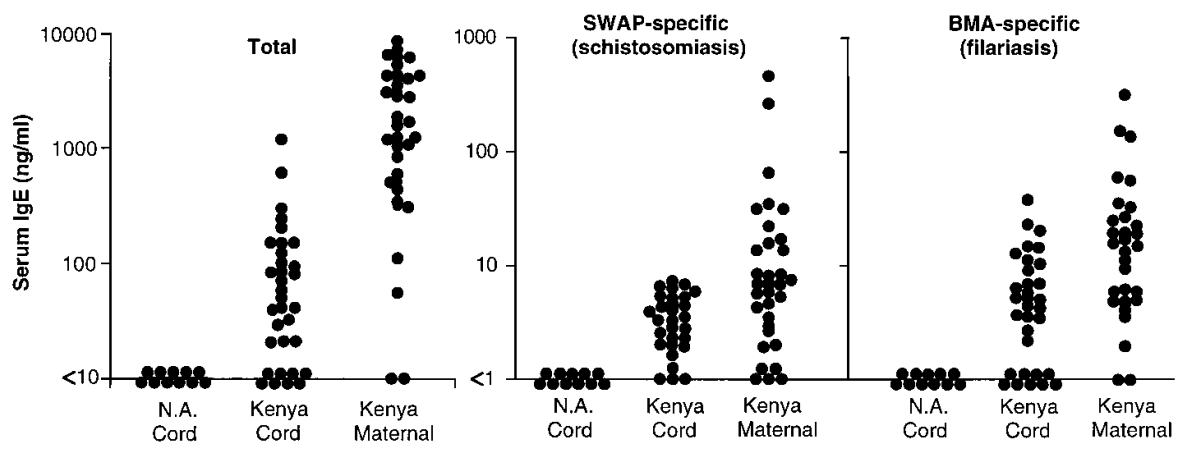

Figure 1. Polyclonal (left), schistosomespecific (middle), and filaria-specific (right) $\mathrm{IgE}$ levels in cord and maternal sera. Each point represents serum levels from a single individual. ulated with helminth and mycobacterial antigens in vitro. These Ags failed to induce IFN- $\gamma$, IL-4, or IL-5 release in North American CBLs (Fig. 3). This supports previous studies showing offspring of healthy mothers contain only naive $\mathrm{T}$ cells incapable of producing these cytokines (36-38). In contrast, 24 and $17 \%$ of Kenyan infants produced detectable levels of SWAP- and BmA-induced IL-5, respectively, and 57 and $28 \%$ produced IFN- $\gamma$ in response to SWAP and BmA, respectively (Fig. 3). Both SWAP and BmA stimulated detectable IL-10 in 41 and $53 \%$ of Kenyan neonates. None of the neo-

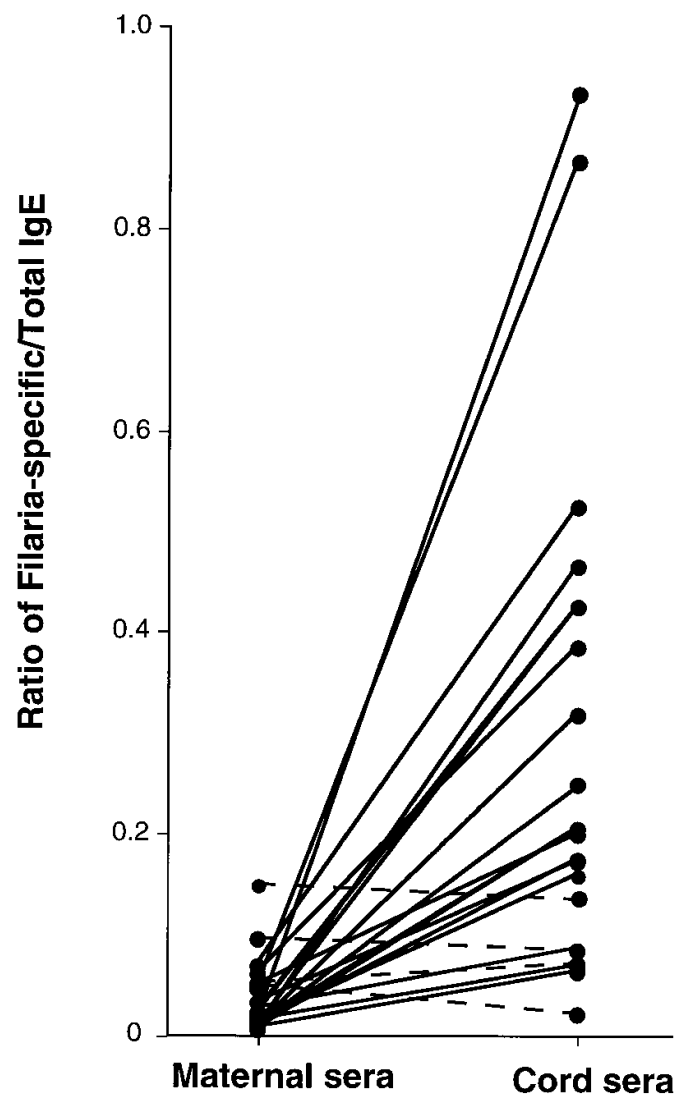

Figure 2. Ratios of filaria-specific IgE to total IgE in maternal-cord serum pairs from Kenya. Ratios in cord sera were greater than three times ratios in maternal sera in 26 of 30 serum pairs (solid lines) indicating a lack of mixing of maternal with fetal blood. In 4 of 30 serum pairs (dashed lines) the ratios were equal indicating that maternal blood may have contaminated the cord serum. nates produced detectable IL-4 in response to Ags. Neonates that stimulated IL-5 in response to BmA or SWAP also produced IFN- $\gamma$, indicating a mixed cytokine response (data not shown). In a subset of neonates Ag-induced IL-2 production by CBLs was also measured. Net SWAP-induced IL-2 was detectable in 6 of 11 subjects (geomean $=11.1$, range 33-394 pg/ $\mathrm{ml}$ ), however 3 of 11 CBLs from North American control individuals also generated detectable IL-2, but at significantly lower levels (geomean $=1.8$, range $26-106 \mathrm{pg} / \mathrm{ml}, P<0.05$ ). One of nine subjects generated BmA-induced IL-2 $(112 \mathrm{pg} / \mathrm{ml})$ while none of the control individuals generated any detectable IL-2 in response to BmA.

The mycobacterial Ag-, PPD-stimulated IFN- $\gamma$ production by CBLs from $30 \%$ of Kenyan neonates and none from the North American babies, but induced small, but equivalent levels of IL-5 and IL-10 from both groups of neonates. PPD also stimulated IL-2 production in three of nine subjects so examined (range 74-215 pg/ml) and none in the control subjects. Neonates that produced PPD-driven IL-2 also generated IFN- $\gamma$. The presence of PPD-driven IL-10 in control subjects likely derives from monocytes and not CD4+ cells (39).

Mitogen-induced IFN- $\gamma$ and IL-10 production varied greatly among CBL from Kenyans compared to CBLs from

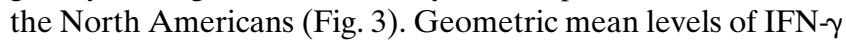
production by Kenyan CBLs (geomean $=3.14 \pm 1.6 \mathrm{ng} / \mu \mathrm{l}$ ) was significantly lower compared to US neonates (geometric mean = $24.7 \pm 7.1 \mathrm{pg} / \mu \mathrm{l} ; P<0.01)$. No significant difference in mitogen-driven IL-10 (Fig. 3) or IL-2 (geomean $=2.35 \pm 1.5 \mathrm{ng} / \mathrm{ml}$ in Kenyan CBLs vs. geomean $=3.4 \pm 0.7 \mathrm{ng} / \mathrm{ml}$ in North American CBL) was observed between the two groups. In contrast, mitogen-driven IL-5 was significantly elevated in 9 of 31 Kenya CBLs compared to North American CBLs (significant levels were considered to be greater than the mean \pm 3 SD of IL-5 production in CBLs from US infants). Mitogen-driven IL-5 production correlated with helminth Ag-driven IL-5 release $(r=0.69 ; P<0.05)$, indicating that expansion of Ag-specific lymphocytes accounts for the increased mitogen-driven IL-5 production. Mitogens failed to induce detectable IL-4 release in CBLs from either Kenyan or North American infants. Overall these results demonstrate that some neonates produced a mixed cytokine response to helminth Ags and Th1-associated cytokine production to PPD.

Helminth and mycobacterial Ags induce a similar pattern of cytokine production in their mothers. To establish whether maternal PBMC generated a similar Ag-specific pattern of cytokine production compared to their offspring, lymphocytes were obtained from the mothers within $24 \mathrm{~h}$ of the time of 


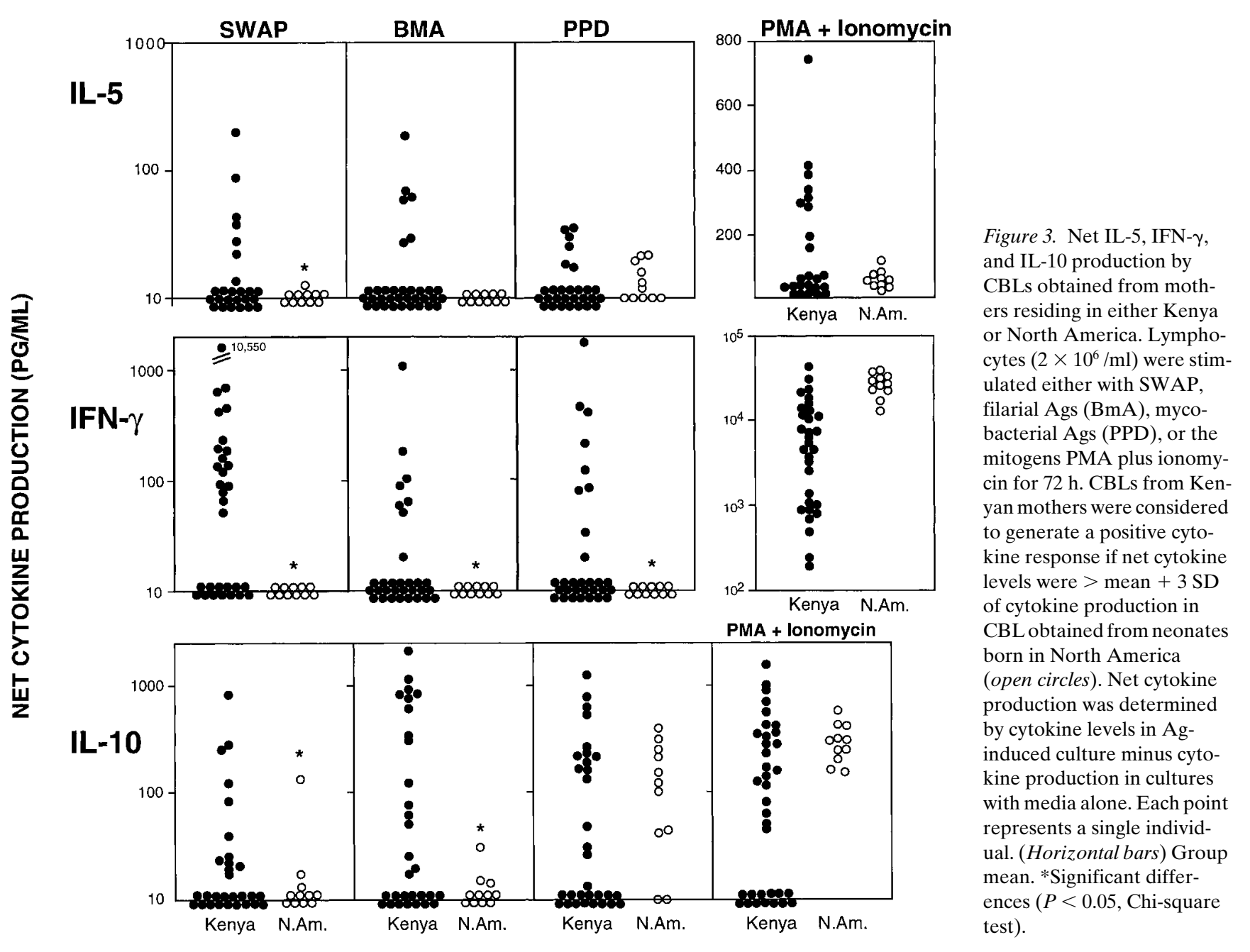

their deliveries. Helminth Ags produced both IFN- $\gamma$ and IL-5 in 54 and/or $65 \%$ of mothers, while PPD stimulated IFN- $\gamma$ release in $77 \%$ of mothers. $30 \%$ of mothers produced IL-5 in response to PPD, but all were at levels $<50 \mathrm{pg} / \mathrm{ml}$ (Fig. 4). The amount of Ag-induced cytokines produced by CBLs and their

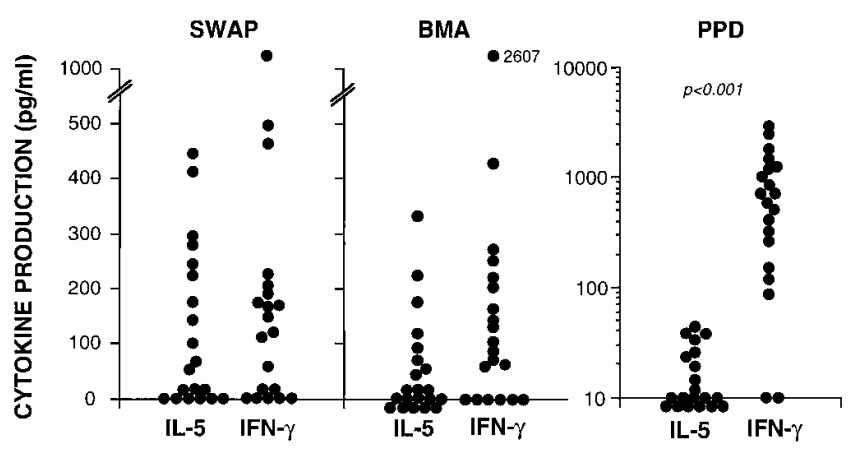

Figure 4. Net Ag-driven IL-5 and IFN- $\gamma$ production by maternal PBMC from Kenya. Lymphocytes were cultured under identical conditions to those described in Fig. 3. Each point represents a single individual. The number of individuals studied were less than that shown in Fig. 3 because peripheral blood could not be obtained from all the mothers. PBMC obtained from US adults $(n=7)$ failed to show any helminth Ag-induced cytokine production (data not shown). mothers failed to correlate $\left(\mathrm{r}^{2}=0.31, P=0.23\right)$. The pattern of cytokine responses in these studies reflect those observed to the same Ags in similar populations with schistosome or filarial infections $(35,39,40)$.

Effect of maternal infection status on Ag-driven cytokine production by $C B L$ s. The infection status of the mothers was not known at the time of delivery, so studies were performed on CBLs obtained from mothers that came from villages known to be highly endemic for these parasitic infections. Because night blood (filariasis) or urine (schistosomiasis) samples were not consistently obtained from all mothers, infection status was determined based on the presence of elevated parasite-specific IgG4, a criterion previously shown to be associated with recent or active infection $(41,42)$. An individual was considered to have elevated serum levels of parasite-specific $\mathrm{IgG} 4$ if the value was greater than the mean $+3 \mathrm{SD}$ of sera obtained from Kenyans living in areas nonendemic for schistosomiasis or filariasis (Turkana District in Northern Kenya; Fig. 5). 15 of 37 mothers of infants shown in Fig. 3 had greater than $630 \mathrm{U}$ of SWAP-specific IgG4, and 12 of 36 mothers examined had greater than $230 \mathrm{U}$ of BmA-specific IgG4 (mean + $3 \mathrm{SD}$ of that observed in nonendemic individuals). Altogether 21 $(57 \%)$ of mothers had either elevated BmA- or SWAP-specific IgG4 levels.

To determine the relationship between the infection status 

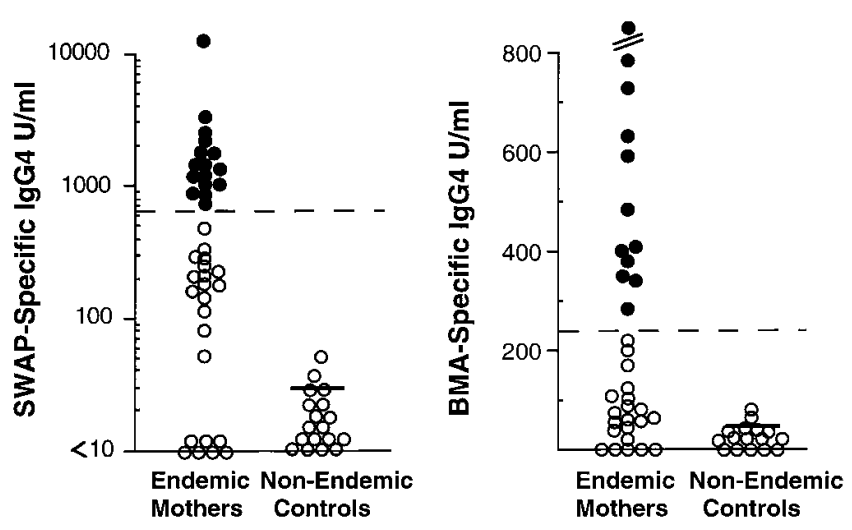

Figure 5. Serum levels of parasite-specific IgG4 from Kenyan mothers or adults residing in the Turkana District of Northern Kenya where there is no schistosomiasis or filariasis (nonendemic controls). (Circle) One individual. (Dashed line) Mean plus three standard deviations of nonendemic controls sera reactivity. (Closed circles) Individuals who have high IgG4 levels and therefore have a recent or active schistosome or filarial infection. (Horizontal lines) Group mean.

of the mother with the ability of the CBLs from their offspring to respond to the appropriate helminth Ag, mothers were categorized according to whether they had elevated parasite-specific IgG4+ levels or not. Fig. $6 \mathrm{~A}$ shows that a significantly greater proportion of CBLs from offspring of infected mothers generated SWAP-driven IL-5 and IL-10 and BmA-induced
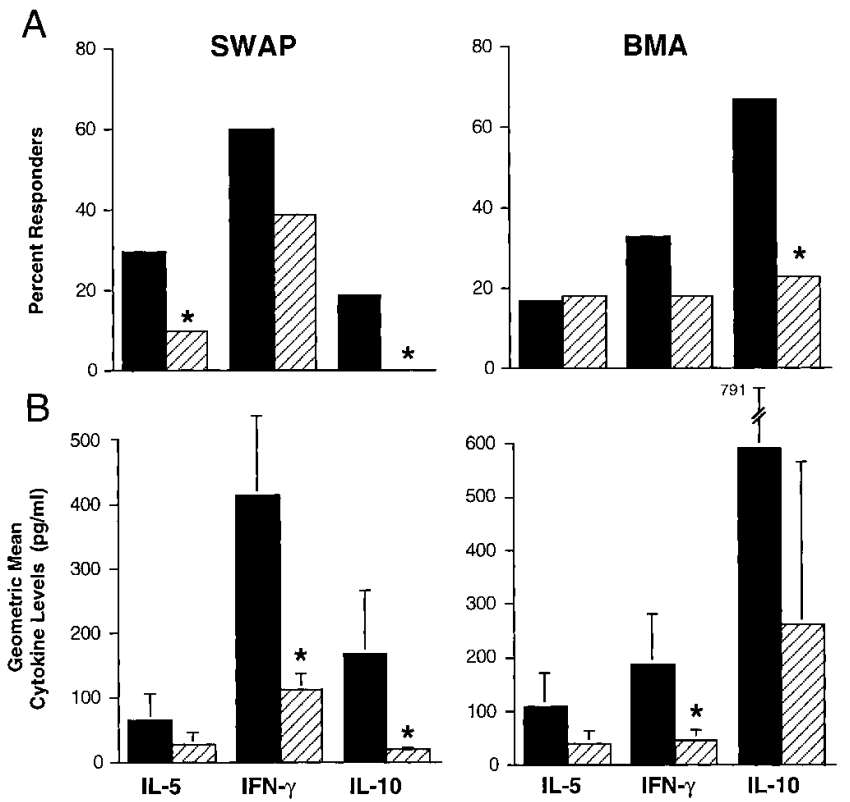

Figure 6. The relationship of maternal infection status with schistosome or filarial Ag-driven cytokine production by CBLs. $(A)$ Percent of CBLs that had significant schistosome $\mathrm{Ag}$ (SWAP)- or filarial $\mathrm{Ag}$ (BMA)-driven cytokine production (from Fig. 3) that were recently or actively infected during pregnancy $(\mathrm{IgG} 4+$, solid bars, $n=16)$ or uninfected (IgG4-, hatched bars, $n=18)$. (B) Geometric means \pm SE levels of cytokine release among CBLs that generated significant cytokine production. *Significant differences between IgG4+ and IgG4- individuals $(P<0.05)$, by Chi-Square test $(A)$, and Student's $t$ test of $\log$ transformed data $(B)$.
IL-10 compared to uninfected subjects. Among CBLs that did respond to helminth Ags, those from infected mothers also produced significantly higher levels of SWAP-induced IFN- $\gamma$ and IL-10 and BmA-induced IL-10 release compared to CBLs obtained from uninfected mothers (Fig. $6 \mathrm{~B}$ ).

The relationship between the PPD status of the mother was also compared to the ability of CBLs of their infants to respond to PPD. Mothers were categorized as PPD responders based on their ability to generate significant levels of PPDdriven IFN- $\gamma$ by their PBMC (see Fig. 4). Among the 20 mothers examined, CBL from seven PPD-responsive neonates had mothers that were also sensitized to PPD while one of eight PPD-sensitized infants had a mother that failed to respond to PPD (Fig. 7; $P<0.05$, Fischer's exact test).

CD4+ lymphocytes in CBLs are the major source of helminth Ag-driven cytokine production. To determine whether $\mathrm{CD} 4+$ are the primary source of Ag-driven cytokine production in CBLs, lymphocytes were obtained from seven additional infants from the same hospital as those described above. Mothers of these infants were either parasitologically positive for schistosomiasis $(n=2)$, had elevated SWAP-specific IgG4 ( $n=2$, see below), were circulating Ag positive for filariasis $(n=2)$, or had elevated BmA-specific IgG4 $(n=1)$. In these subjects, cytokine production was performed by ELISPOT to determine frequencies of Ag-specific cytokine secreting cells and to evaluate whether CBLs were capable of IL-4 production that had not been detectable in culture supernatants. All seven CBLs from these neonates secreted IL-5, IL-4 and/or IL-10 in response to schistosome or filarial antigen at frequencies of 1 in $10^{5}$ to $1-2$ in $10^{4}$ cells (four individuals are shown in Fig. 8), frequencies comparable to that observed by ELISPOT in PBMC from filarial infected individuals in India (35). For most of the seven neonates studied, frequencies of IFN- $\gamma$ secreting cells were lower than the other cytokines; in the range of $1-5$ in $10^{5}$ CBLs. Depletion of CD4+ cells significantly reduced or abolished detectable cytokine secreting cells by CBLs from all neonates studied indicating CD4+ cells were the predominant cell type for Ag-induced cytokine production. In four of the seven patients examined CD4+ cells were simultaneously enriched by immunomagnetic positive selec-

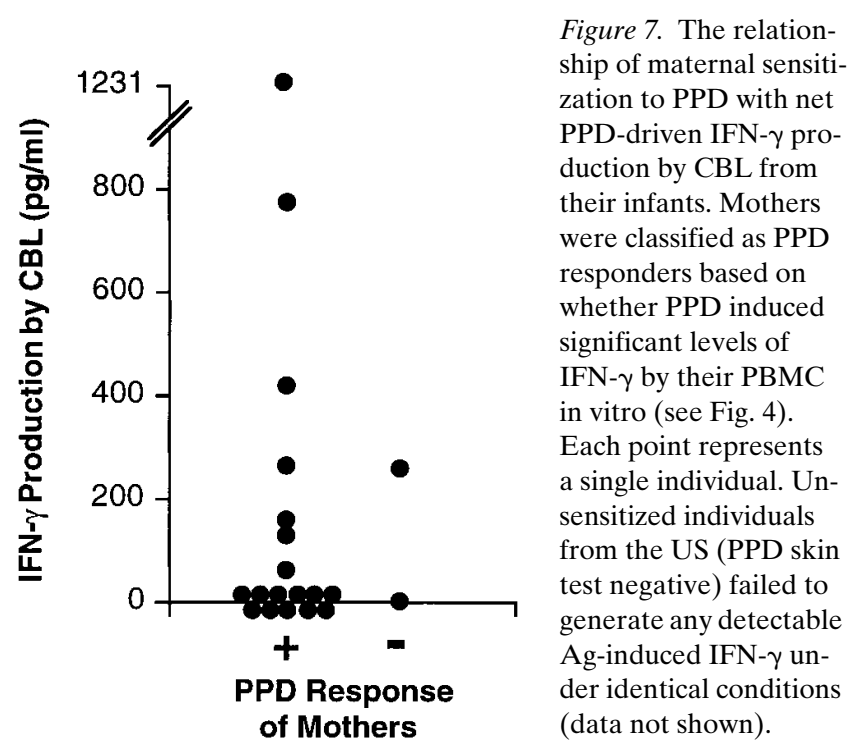




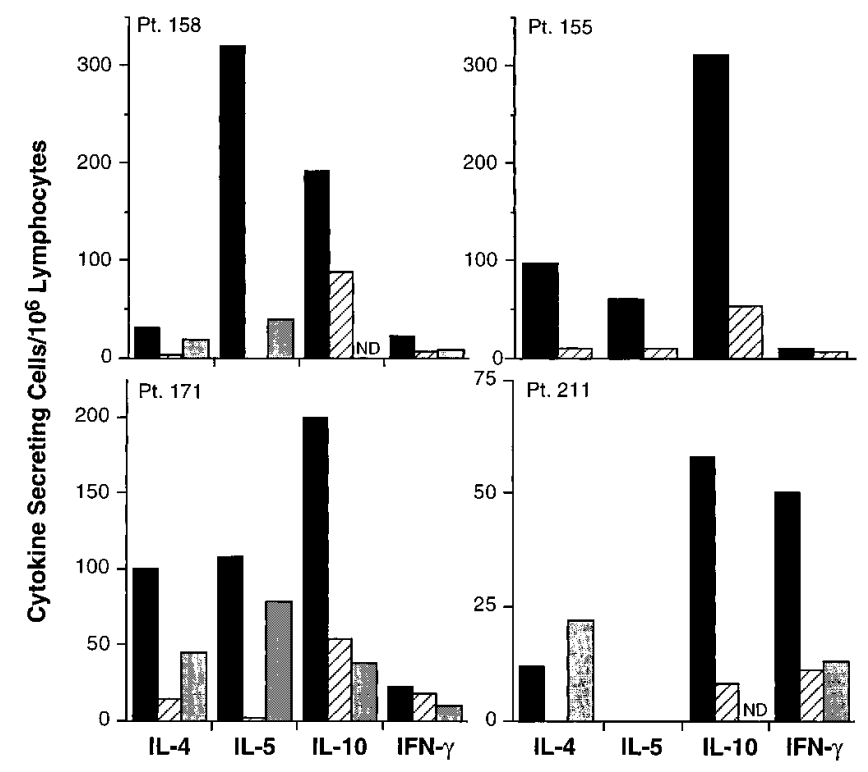

Figure 8. The effect of CD4+ cell depletion on the frequency of helminth Ag-induced cytokine secreting cells in CBLs from neonates born of mothers infected with filariasis (patients 171 and 211) or schistosomiasis (patients 158 and 155$)$. CBLs $\left(0.5-1 \times 10^{6}\right.$ per well in the ELISPOT plate) were stimulated with either BmA (filarial infected patients) or SWAP (schistosome infected patients; solid bars) for 24 or $48 \mathrm{~h}$ depending on the cytokine as described in Methods. In parallel cultures, CBLs were initially depleted of CD4+ cells by immunomagnetic negative selection (hatched bars) and then cultured under identical conditions as whole CBLs. In some individuals CD4+ were immunomagnetically positively selected and cultured under conditions described in Methods (shaded bars). These results are representative of a total of seven CBLs studied. (ND) Assay was not performed for this cytokine.

tion and stimulated with helminth and/or mycobacterial antigens depending on the number of cells recovered (patients 158, 155, and 171; Fig. 8). Frequencies of cytokine-secreting cell determined by positive selection corresponded to those observed by depletion of CD4+ cells (Fig. 8).

Although insufficient cell number precluded examining PPD driven responses in all patients, in three of the patients examined (that included patients 171 and 155; Fig. 8), no PPDdriven IL-4 or IL-5 secreting cells were detected, however frequences of IFN- $\gamma$ secreting cells were 46, 130, and 194 per $10^{6}$ CBLs, respectively. Depletion of $\mathrm{CD} 4+$ cells markedly reduced frequencies to 10,2 , and 7 cells per $10^{6} \mathrm{CBLs}$, respectively.

\section{Discussion}

Helminth Ag-specific hyporesponsiveness observed among infected individuals with schistosomiasis or filariasis residing in endemic areas has been postulated to result from in utero exposure to parasite antigens $(5,6,14,35,43,44)$. The mechanisms for this immune hyporesponsiveness may result through clonal deletion or anergy of Ag-reactive lymphocytes to render the child hyporesponsive to parasite Ags when subsequently infected (44). Alternatively, neonatal exposure to Ags may bias toward a Th2 response (29). Results presented here reject both of these hypotheses and show that offspring from helminth-exposed mothers become sensitized to helminth and mycobacterial Ags in utero to produce a pattern of cytokine responses similar to that observed in adults $(35,39)$. Schistosome and filarial Ags stimulated IL-4, IL-5, and IL-10 production, but also IFN- $\gamma$ release by CBLs while PPD-induced predominantly a IFN- $\gamma$ response. Indeed, previous studies show neonates can develop immunologic reactivity in vitro with immunization of pregnant mothers with various vaccines (21-23) or with infections during pregnancy $(19,20,24,25)$ although the type of immune response had not been previously defined. Recent studies in neonatal mice also show that $\mathrm{Ag}$ or allogenic lymphocyte exposure does not produce tolerance (45-47) and the data presented here extends these findings to natural infections in humans.

It is unlikely that the observations reported here could be due to the mixing of maternal cells and antibody at birth for several reasons. First, using an analysis developed by Weil et al. (5), the proportion of filarial-specific $\mathrm{IgE}$ to total $\mathrm{IgE}$ in the cord blood was at least threefold greater in cord blood sera than maternal sera in all but four individuals. Because maternal IgE levels are generally much higher than their offspring, significant mixing of maternal blood with cord blood should produce equivalent ratios. This occurred in only four BmAspecific pairs, although similar ratios could develop by chance and not by mixing. Second, mixing of maternal and fetal blood at birth occasionally occurs (48), but usually produces a graftversus-host reaction in vivo and/or a mixed lymphocyte reaction in vitro (49). However, neither of these phenomena were observed in the babies nor CBL cultures in the present study. Finally, levels of Ag- or mitogen-specific cytokine production by paired cord and maternal lymphocytes did not correlate as might be expected if maternal-fetal mixing of blood were common at birth.

The mechanisms by which the fetus becomes exposed to parasite Ags in utero is uncertain. Although direct adherence of malaria-infected erythrocytes to chondroitin sulfate A in human placenta has been recently shown (50), accumulation of schistosomiasis, lymphatic filariasis, or intestinal helminths rarely occurs in the human fetus (51). Instead, in utero sensitization could result from transplacental transfer of $\mathrm{Ag}$ (52) and exposure of the fetal immune system. The intravascular location of schistosome and filarial parasites ensure that much of their metabolic products and secretions enter the circulation, a finding that has been shown by detection of circulating $\mathrm{Ag}$ in the serum, milk, and urine of infected individuals (52-55). Alternatively, transplacental transfer of antiidiotypic $\mathrm{Ab}$ may also sensitize the fetus (27).

$30 \%$ of Kenyan neonates produced significant levels of PPD-induced IFN- $\gamma$ by CBL and little or no IL-5. None of CBLs from US neonates produced IFN- $\gamma$ in response to PPD indicating that a mitogenic effect was unlikely. BCG vaccination and tuberculosis are common in Kenyans and over $75 \%$ of the mothers responded to PPD. The mechanisms of prenatal sensitization may be similar to those postulated for helminth antigens.

The failure of CBLs from many offspring of apparently infected mothers to produce detectable cytokines may result from several causes. It is theoretically possible that these neonates have become exposed to $\mathrm{Ag}$ in utero and become tolerized and therefore fail to respond to helminth Ags. To examine this possibility, we would predict that these children should remain hyporesponsive to helminth Ags as they become ex- 
posed to subsequent infection, an aspect of the present study currently under investigation. However, we favor alternative explanations. For example, neonates may become sensitized in utero, but cytokine production is below the limit of detection with our current assays. Indeed, some of these cytokine unresponsive neonates had polyclonal and/or parasite $\operatorname{IgE}$ in their cord sera. Another explanation is that insufficient Ag crosses the placenta to sensitize the fetal immune system. In this case it would be predicted that the more heavily infected mothers sensitize their offspring. We observed that the three mothers with the highest schistosome-specific IgG4 Ab levels all showed Ag-specific cytokine responses by CBLs in their offspring.

Some CBLs from uninfected mothers did respond to helminth antigens. This likely results from cross-reactivity to other helminth infections. CBLs from four neonates responded to schistosome antigens, but were not infected with schistosomiasis although they had been exposed/infected with filariasis or vice versa. CBLs from two other offspring that responded to helminth Ags had neither filariasis or schistosomiasis. In this case, cross-reactivity may have been to intestinal helminth infections which are common in our Kenyan study populations (personal observations). CBLs from neonates that produced IFN- $\gamma$ in response to PPD had mothers that were also sensitized to PPD, except for one infant. In the one individual, the mother may have been anergic to PPD, either because of reactivation of latent infection, concomitant infections such as malaria or HIV, or had developed an early primary infection.

Our studies suggest the helminth Ag-specific hyporesponsiveness of individuals living in areas endemic for helminth infections may have less to do with prenatal exposure than other factors such as host genetic differences, chronicity of infection, or repeated exposure to infective stages of the parasite. Yet, how in utero exposure to chronic infections such as schistosomiasis, filariasis, or mycobacterial diseases affects subsequent immune response with later reexposure remains poorly understood.

\section{Acknowledgments}

We appreciate the assistance of M. Odera in help with the data management. We thank the nurses at the Msambweni District Hospital, Nairobi, Kenya, who collected the cord blood samples. Most of all we appreciate the cooperation of the mothers who agreed to participate in this study. Drs. Ron Blanton, Fred Heinzel, Adel Mahmoud, and Eric Pearlman have provided valuable advice throughout the study and helpful comments on the manuscript.

\section{References}

1. Lewert, R.M., and S. Mandlowitz. 1969. Schistosomiasis: Prenatal induction of tolerance to antigens. Nature (Lond.). 224:1029-1030.

2. Klei, T.R., D.P. Blanchard, and S.U. Coleman. 1986. Development of Brugia pahangi infections and lymphatic lesions in male offspring of female jirds with homologous infections. Trans. R. Soc. Trop. Med. Hyg. 80:214-216.

3. Billingham, R., L. Brent, and P.B. Medawar. 1953. Actively acquired tolerance of foreign cells. Nature (Lond.). 172:603-605.

4. Burnet, F., and F. Fenner. 1949. The Production of Antibodies. MacMillan, Melbourne. 102-105 pp.

5. Weil, G.J., R. Hussain, V. Kumaraswami, S.P. Tripathy, K.S. Phillips, and E.A. Ottesen. 1983. Prenatal allergic sensitization to helminth antigens in offspring of parasite-infected mothers. J. Clin. Invest. 71:1124-1129.

6. Steel, C., A. Guinea, J.S. McCarthy, and E.A. Ottesen. 1994. Long-term effect of prenatal exposure to maternal microfilaremia on immune responsiveness to filarial parasite antigens. Lancet. 343:890-893.

7. King, C.L., and T.B. Nutman. 1991. Regulation of the immune response in lymphatic filariasis and onchocerciasis. Immunol. Today. 12:A54-A58.

8. Newport, G.R., and D.G. Colley. 1993. Schistosomiasis. In Immunology and Molecular Biology of Parasitic Infections. K.S. Warren, editor. Blackwell Scientific Publications, Oxford.

9. Lambert, A.C. 1911. Fevers with urticaria and esosinophila and their relation to infection with Schistosoma japonicum. Trans. R. Soc. Trop. Med. Hyg. $5: 38-45$

10. Gelfand, M. 1964. The hypersensitive response of the European to schistosomiasis. J. Trop. Med. Hyg. 67:255-256.

11. Partono, F., W. Purnomo, A. Pribadi, and A. Soewarta. 1978. Epidemiological and clinical features of Brugia timori in a newly established village, Karakuak, West Flores, Indonesia. Am. J. Trop. Med. Hyg. 27:910-915.

12. Prost, A., and E.G. Ponsay. 1979. Importance epidemiologique du parasitisme neo-natal par microfilaries donchocerca volvulus. Tropenmed. Parasitol. 30:477-481.

13. Wartman, W.B. 1947. Filariasis in American armed forces in World War II. Medicine. 26:333-394.

14. Lammie, P., W. Hitch, A. Walker, W. Hightower, and M. Eberhard 1991. Maternal filarial infection as risk factor for infection in children. Lancet. 337:1005-1006.

15. Haque, A., W. Cuna, J. Pestel, A. Capron, and B. Bonnel. 1988. Tolerance in rats by transplacental transfer of Dipetalonema viteae microfilariae: recognition of putative toleragen(s) by antibodies that inhibit antigen-specific lymphocyte proliferation. Eur. J. Immunol. 18:1167-1172.

16. Haque, A., and A. Capron. 1982. Transplacental transfer of roden microfilariae induces antigen-specific tolerance in rats. Nature (Lond.). 299:361363.

17. Schrater, A., A. Spielman, and W. Piessens. 1983. Predisposition to Brugia malayi microfilaremia in progeny of infected gerbils. Am. J. Trop. Med. Hyg. 32:1302-1308.

18. Hang, L., D. Boros, and K. Warren. 1974. Induction of immunological hyporesponsiveness to granulomatous hypersensitivity in Schistosoma mansoni infection. J. Infect. Dis. 130:515-522.

19. Aase, J.M., G.R. Noren, D.V. Reddy, and J.W. St. Geme, Jr. 1972 Mumps-virus infection in pregnant women and the immunologic response of their offspring. N. Eng. J. Med. 286:1379-1382.

20. Hara, T., S. Ohashi, Y. Yamashita, T. Abe, H. Hisaeda, K. Himeno, R.A. Good, and K. Takeshita. 1996. Human V $\delta 2+\gamma \delta$ T-cell tolerance to foreign antigens of Toxoplasma gondii. Proc. Natl. Acad. Sci. USA. 93:5136-5140.

21. Gill, T.J.I., C.F. Repetti, L.A. Metlay, B.S. Rabin, F.H. Taylor, D.S. Thompson, and A.L. Cortese. 1983. Transplacental immunization of the human fetus to tetanus by immunization of the mother. J. Clin. Invest. 72:987-996.

22. Baker, C.J., M.A. Rench, M.S. Edwards, R.J. Carpenter, B.M. Hays, and D.L. Kasper. 1988. Immunization of pregnant women with a polysaccharide vaccine of group B streptococcus. N. Engl. J. Med. 319:1180-1185.

23. McCormick, J.B., H.H. Gusmao, S. Nakamura, J.B. Freire, J. Veras, G. Gorman, J.C. Felley, and P. Wingo. 1980. Antibody response to serogroup A and $\mathrm{C}$ meningococcal polysaccharide vaccines in infants born of mothers vaccinated during pregnancy. J. Clin. Invest. 65:1141-1144.

24. Camus, D., Y. Carliere, J.C. Bina, R. Borojevic, A. Prata, and A. Capron. 1976. Sensitization to Schistosoma mansoni antigen in uninfected children born to infected mothers. J. Infect. Dis. 134:405-408.

25. Tachon, P., and R. Borojevic. 1978. Mother-child relation in human schistosomiasis mansoni: skin test and cord blood reactivity to schistosomal antigens. Trans. R. Soc. Trop. Med. Hyg. 72:605-609.

26. Agarwal, M., G. Prasad, B. Harinath, and B. Bhatia. 1986. Transplacental transfer of filarial infection. Indian Pediatr. 23:169-174.

27. Eloi-Santos, S.M., E. Novata-Silva, V.M. Maselli, G. Gazzinelli, D.G. Colley, and R. Correa-Oliveira. 1989. Idiotypic sensitization in utero of children born to mothers with schistosomiasis or Changas' disease. J. Clin. Invest. 84: 1028-1031.

28. Novato-Silva, E., G. Gazzinelli, and D.G. Colley. 1992. Immune responses during human schistosomiasis mansoni. XVIII. Immunologic status of pregnant women and their neonates. Scand. J. Immunol. 35:429-437.

29. Barrios, C., P. Brawand, M. Berney, C. Brandt, P.-H. Lambert, and C.-A Siegrist. 1996. Neonatal and early life immune responses to various forms of vaccine antigens qualitatively differ from adult responses: predominance of a Th2-biased pattern which persists after adult boosting. Eur. J. Immunol. 26: 1489-1496.

30. Boros, D.V., and K.S. Warren. 1970. Delayed hypersensitivity-type granuloma formation and dermal reaction induced and elicited by a soluble factor isolated from schistosoma mansoni eggs. J. Exp. Med. 132:488-507.

31. Hussain, R., R.G. Hamilton, V. Kumaraswami, N.F. Adkinson, and E.A. Ottesen. 1981. IgE response in human filariasis. I. Quantitation of filariaspecific IgE. J. Immunol. 127:1623-1629.

32. de Waal Malefyt, R., J. Haanen, H. Spits, M. Roncarolo, A. te Velde, C Figdor, K. Johnson, R. Kastelein, H. Yssel, and J. de Vries. 1991. Interleukin 10 (IL-10) and viral IL-10 strongly reduce antigen-specific human T cell proliferation by diminishing the antigen-presenting capacity of monocytes via downregulation of class II major histocompatibility complex expression. J. Exp. Med. 174:915-924.

33. Mahanty, S., J.S. Abrams, C.L. King, A.P. Limaye, and T.B. Nutman. 
1992. Parallel regulation of IL-4 and IL-5 in human helminth infections. J. Immunol. 148:3567-3571.

34. Li, Z., C.L. King, J.O. Ogundipe, L.S. Licate, and R.E. Blanton. 1995. Preferential recognition by human IgE and IgG4 of a species-specific Schistosoma haematobium serine protease inhibitor. J. Infect. Dis. 171:416-422.

35. King, C.L., S. Mahanty, V. Kumaraswami, J.S. Abrams, J. Regunathan, K. Jayaraman, E.A. Ottesen, and T.B. Nutman. 1993. Cytokine control of parasite-specific anergy in human lymphatic filariasis. J. Clin. Invest. 92:1667-1673.

36. Roncarolo, M.-G., M. Bigler, E. Ciuti, S. Martino, and P.-A. Tovo. 1994. Immune responses by cord blood cells. Blood Cells (Berlin). 20:573-586.

37. King, C.L., R.J. Stupi, N. Craighead, C.H. June, and G. Thyphronitis. 1995. CD28 activation promotes Th2 subset differentiation by human CD4+ cells. Eur. J. Immunol. 25:587-595.

38. Wilson, C.B., D.B. Lewis, and B.K. English. 1991. T cell development of the fetus and neonate. In Immunology of Milk and the Neonate. J. Mestecky, C. Blair, and P.L. Ogra, editors. Plenum Press, New York. 17-29.

39. King, C.L., A. Medhat, I. Malhotra, M. Nafeh, A. Helmy, J. Khaudary, S. Ibrahim, M. El-Sherbiny, S. Zaky, R. Stupi, et al. 1996. Cytokine control of parasite parasite-specific anergy in human urinary schistosomiasis: IL-10 modulates lymphocyte reactivity. J. Immunol. 156:4715-4721.

40. King, C.L., J. Hakimi, M.T. Shata, and A. Medhat. 1995. IL-12 regulation of parasite antigen-driven $\mathrm{IgE}$ production in human helminth infections. $J$. Immunol. 155:454-461.

41. Lal, R.B., and E.A. Ottesen. 1988. Enhanced diagnostic specificity in human filariasis by IgG4 antibody assessment. J. Infect. Dis. 158:1034-1039.

42. Iskander, R., P.K. Das, and R.C. Aalberse. 1981. IgG4 antibodies in Egyptian patients with schistosomiasis. Int. Archs. Allergy Appl. Immunol. 66: 200-218.

43. Ottesen, E.A. 1984. Immunological aspects of lymphatic filariasis and onchocerciasis in man. Trans. R. Soc. Trop. Med. Hyg. 78(Suppl.):9-18.

44. Nutman, T.B., V. Kumaraswami, and E.A. Ottesen. 1987. Parasite-specific anergy in human filariasis. Insights after analysis of parasite antigen-driven lymphokine production. J. Clin. Invest. 79:1516-1523.

45. Ridge, J.P., E.J. Fuchs, and P. Matzinger. 1996. Neonatal tolerance revisited: turning on newborn T cells with dendritic cells. Science (Wash. DC). 271:1723-1726.

46. Forsthuber, T., and H.C. Yip. 1996. Induction of Th1 and Th2 immunity in neonatal mice. Science (Wash. DC). 271:1728-1730.

47. Pennisi, E. 1996. Teetering on the brink of danger. Science (Wash. DC). 271:1665-1667.

48. Schroder, J. 1974. Passage of leukocytes from mother to fetus. Scan. J. Immunol. 3:369-373.

49. Grogan, T., D. Broughton, and W. Doyle. 1975. Graft-versus-host reaction (GVHR): a case report suggesting GVHR occurred as a result of maternofetal cell transfer. Arch. Pathol. 99:330-334.

50. Fried, M., and P.E. Duffy. 1996. Adherence of Plasmodium falciparum to chondroitin sulfate A in the human placenta. Science (Wash. DC). 272:15021504.

51. Raghavan, N.G.S. 1958. Congenital filariasis. Bull. Nat. Soc. Indian Mal. Mosz. Dis. 6:147-154.

52. Carlier, Y., H. Nzeyimana, D. Bout, and A. Capron. 1980. Evaluation of circulating antigens by a sandwich radioimmunoassay, and of antibodies and immune complexes, in Schistosoma mansoni-infected African parturients and their newborn children. Am. J. Trop. Med. Hyg. 29:74-81.

53. Carlier, Y., D. Bout, J. Bina, D. Camus, J. Figueiredo, and A. Capron. 1975. Immunological studies in human schistosomiasis. I. Parasitic antigen in urine. Am. J. Trop. Med. Hyg. 24:949-954.

54. Santoro, F., Y. Carlier, R. Borojevic, D. Bout, P. Tachon, and A. Capron. 1976. Parasite "M" antigen in milk from mothers infected with Schistosoma mansoni (preliminary report). Ann. Trop. Med. Parasitol. 71:121-123.

55. Deelder, A., and T. Nash. 1985. Comparison of four schistosome excretory-secretory antigens: Phenol sulfuric test active peak, cathodic circulating antigen, gut-associated proteoglycan, and circulating anodic antigen. Am. J. Trop. Med. Hyg. 34:236-241. 